\title{
Journal of Dentistry and Oral Care
}

\section{Restoring Aesthetics with Immediate Implant - A Case Report}

\author{
Col SK Rath ${ }^{1}$, Umesh Kumar ${ }^{2 *}$
}

${ }^{1}$ Classified Spl (Periodontics), Commanding Officer and Corps Dental Advisor, 9 Corps Dental Unit, Yol Cantt, Himachal Pradesh ${ }^{2}$ Dental Officer, 9 Corps Dental Unit, Yol Cantt, Himachal Pradesh

*Corresponding author: Dr. Umesh kumar, Dental Officer, 9 Corps Dental Unit, Yol Cantt, Himachal Pradesh, E-mail: umeshchandolia@rediffmail.com

Citation: Kumar, U., et al. Restoring Aesthetics with Immediate Implant - A Case Report. (2016) J Dent Oral Care 2(2): 105- 108.

Keywords: Early loading; Fresh extraction socket; Gingival architecture immediate placement; Zirconia crown; Angulated abutment; Gingival prosthesis
Received date: November 13, 2016

Accepted date: December 28, 2016

Published date: December 30, 2016

DOI: $10.15436 / 2379-1705.16 .1218$

\section{Introduction}

Loss of tooth in the aesthetic zone is a traumatic experience with or without compromise in phonetics. Hence, in the aesthetic zone implant supported single tooth replacement is one of the most challenging situations confronting the clinician. According to the traditional protocols 3-4 months of healing period is required for the consolidation of extraction socket. Taking into account the prosthetic treatment, patients frequently are required to wait up to 1 year for replacement of a lost tooth ${ }^{[1]}$. Attempts to shorten the overall length of treatment period have focussed on approaches like early or immediate loading following implant placement, immediate implant placement in fresh extraction site, and immediate implant placement and early or immediate loading ${ }^{[2-4]}$. The concept of immediate implant loading has recently become popular due to less trauma, reduction in overall treatment time, decrease in hard and soft tissue resorption increase in patient's acceptance, along with better function, aesthetics and has a psychological benefit also ${ }^{[5,6]}$. In this case report the harmony of soft and hard tissue was preserved by immediate implant placement and early loading in anterior maxilla with a gingival prosthesis .

\section{Case report}

A 15 year old female patient daughter of a serving soldier presented to the Department of Dental Surgery, 9 Corps Dental Unit with chief complaint of fractured upper front tooth due to trauma since last four years. Clinical and radiographic examination revealed fractured upper right central incisor with coronal part of crown lying sub gingival with unfavorable prognosis in response to any type of conservative treatment (Figure 1). RVG examination revealed that the tooth was an old case of root canal treated tooth without any periapical involvement. The patient was given a detailed explanation concerning the present state, alternative treatment plans and the proposed procedure which included immediate implant placement and early loading.

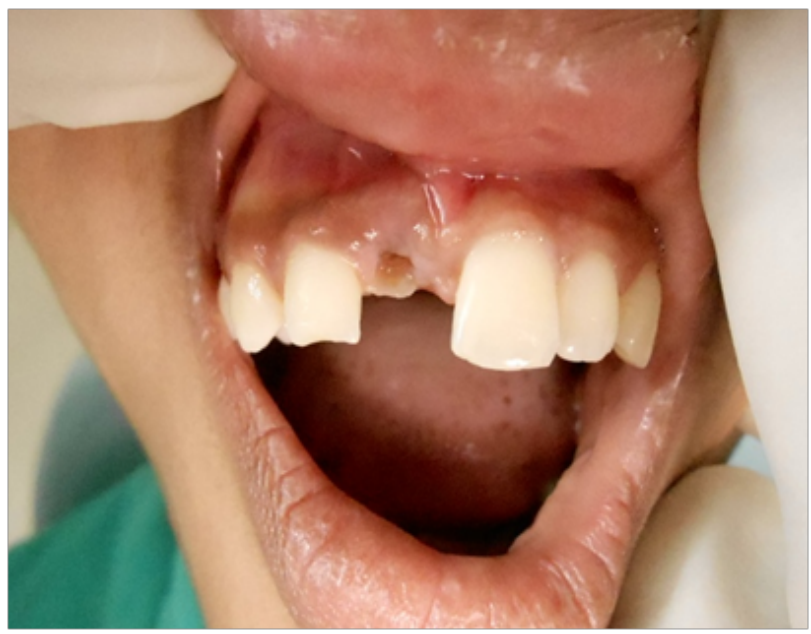

Figure 1: photograph showing broken Maxillary right central Incisor.

The patient was very conscious about her anterior aesthetics and was very keen for earliest possible restoration of her teeth and probably for that she opted for proposed proce- 
dure. Pre-surgical radiographic evaluation was carried out with RVG, panoramic radiograph for appropriate treatment planning (Figure $2 \& 3$ ). Systemic examination of the patient revealed no abnormality and routine blood investigation was carried out to exclude any such complications. The pre operative clinical and radiological examination was undertaken for assessment of height of existing retained root for height of future implant and width of socket. The width of the implant was selected one size more than the existing socket width. After pre surgical assessment, NORIS implant with a size of $(10 \times 3.3)$ measuring $\mathrm{mm}$ in dimension was selected for placement.

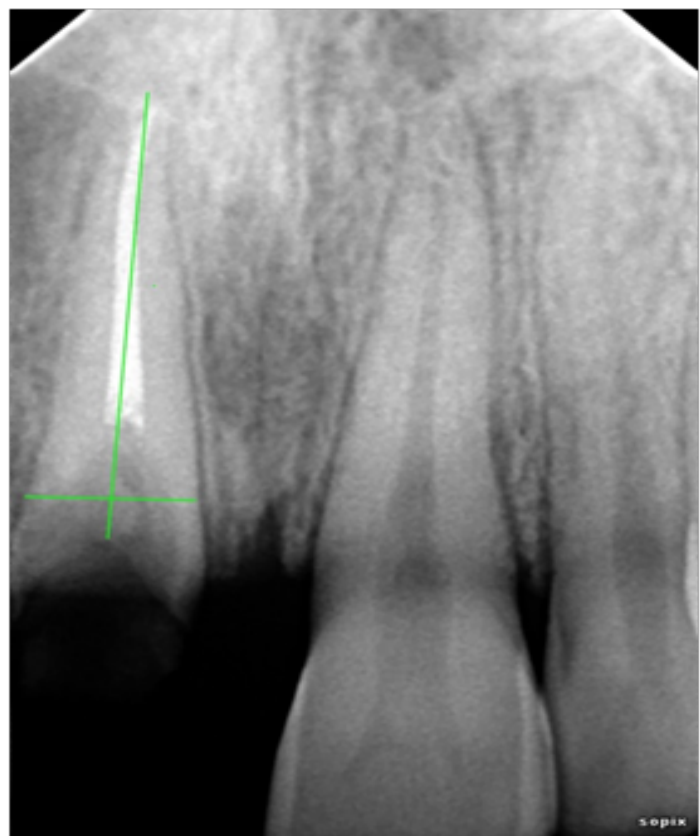

Figure 2: RVG showing a case of root canal treated tooth without any peri apial involvement.

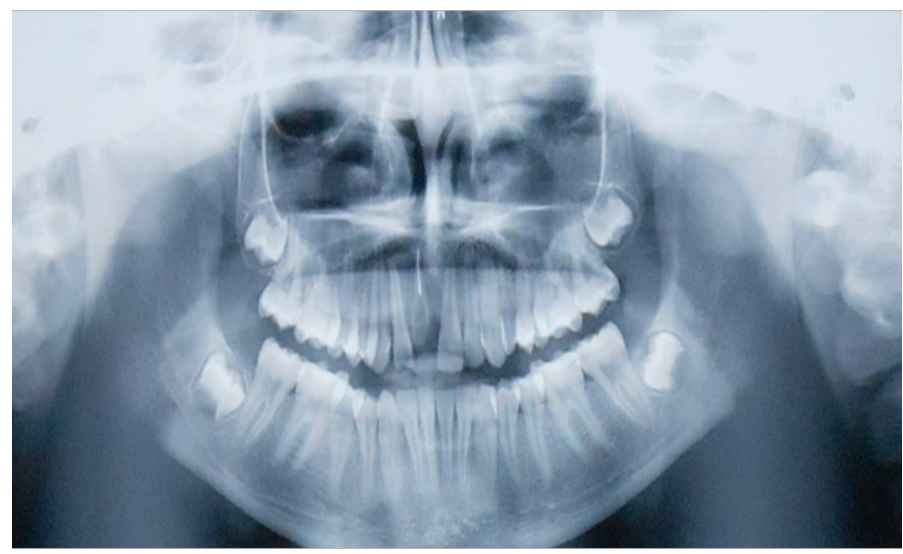

Figure 3: Pre-sugical panoramic radiograph.

Following an injection of $2 \%$ lidocaine with 1: 100,000 epinephrine local anesthetics with infiltration, maximum care was undertaken for a traumatic extraction of the affected tooth and preserve the available cortical bone (Figure 4). The resulting extraction socket was evaluated for osseous defects. All four walls were found intact. The extraction socket was thoroughly debrided and after sequential drilling implant was placed in socket with the insertion torque of 40 (Figure $5 \& 6$ ).

Implant first thread was placed $.5 \mathrm{~mm}$ apical to crestal bone of the socket and adequate primary stability was obtained.
Suturing was done to appose the soft tissue for better healing which was removed 10 days post operatively. Healing cap was secured on the implant. Appropriate antibiotic (amoxiclav 625 $\mathrm{mg}, 2$ times daily for 5 days) and analgesic (ibuprofen $400 \mathrm{mg}$, every 8 hourly as needed) were prescribed and post operative instructions were given.

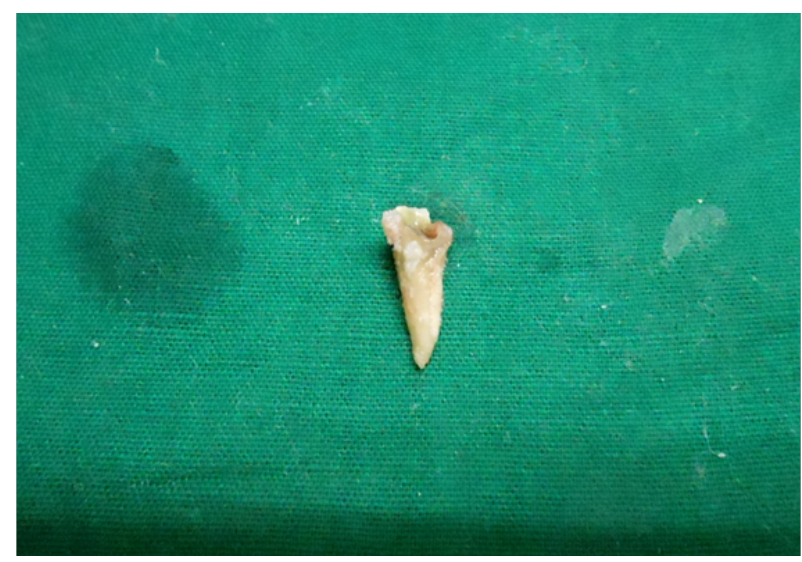

Figure 4: Extracted tooth.

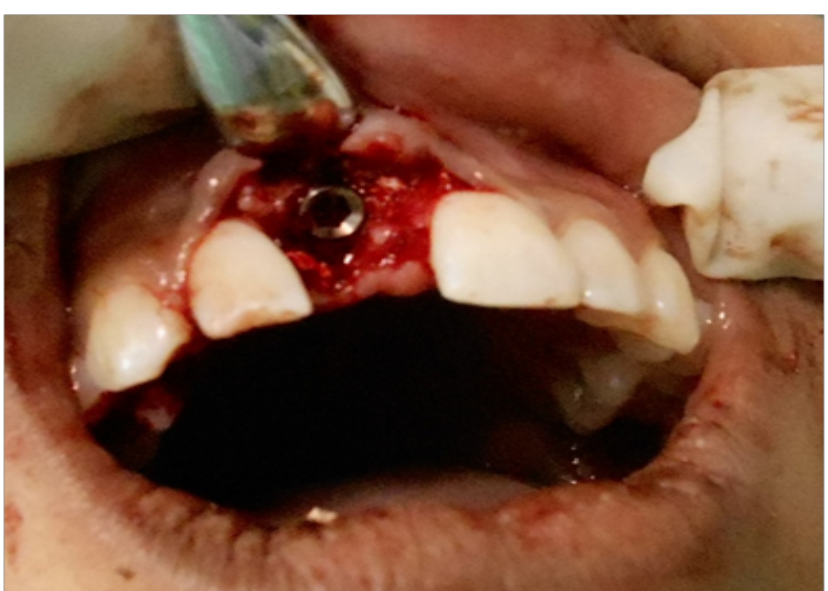

Figure 5: Implant placed in the socket.

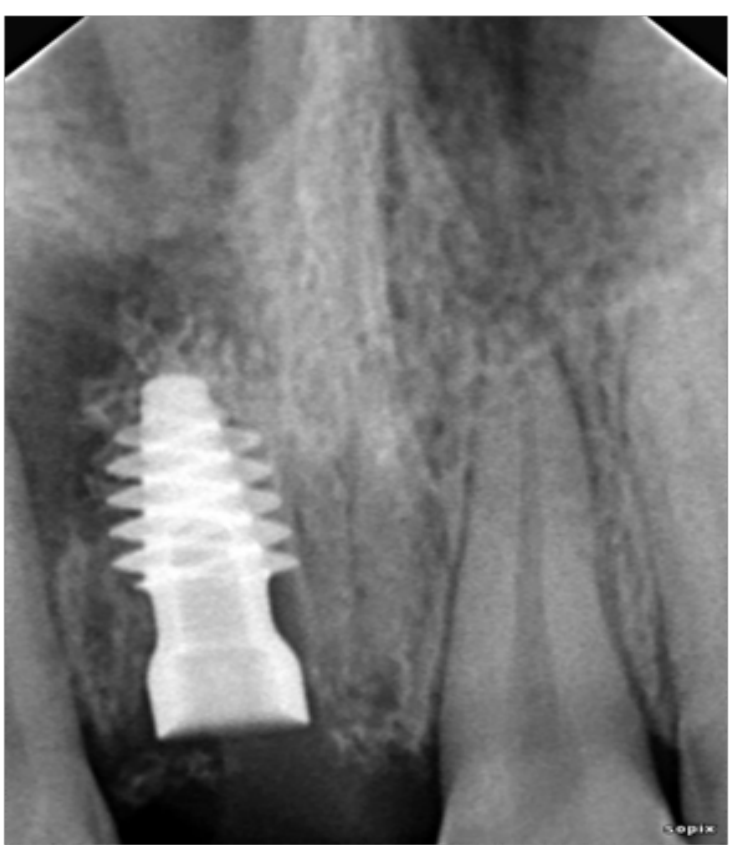

Figure 6: Post operative RVG. 
The patient was reviewed and second surgery was performed after three and half months where a 15 degree angulated abutment (Figure 7) was fitted on the implant for correcting angulations. Subsequently the zirconium crown with gingival prosthesis (Figure $8 \& 9$ ) in the apical portion of crown was fixed with cementation on the abutment to mask the exposure of apical portion of implant enhancing the esthetic value and patient satisfaction.

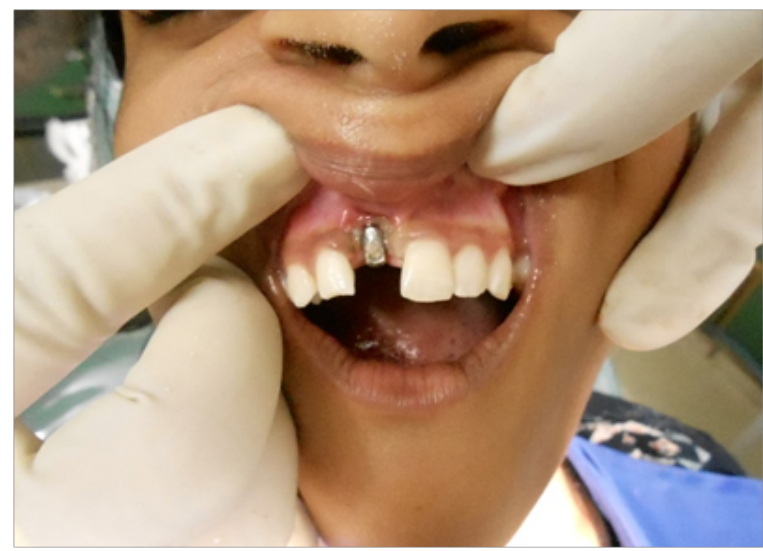

Figure 7: Angulated abutment placement.

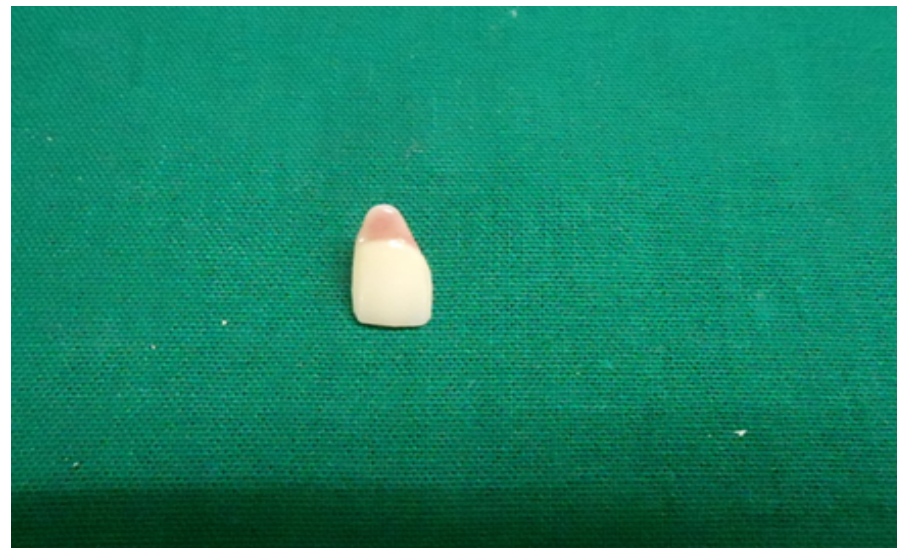

Figure 8: Zirconia Crown with gingival prosthesis.

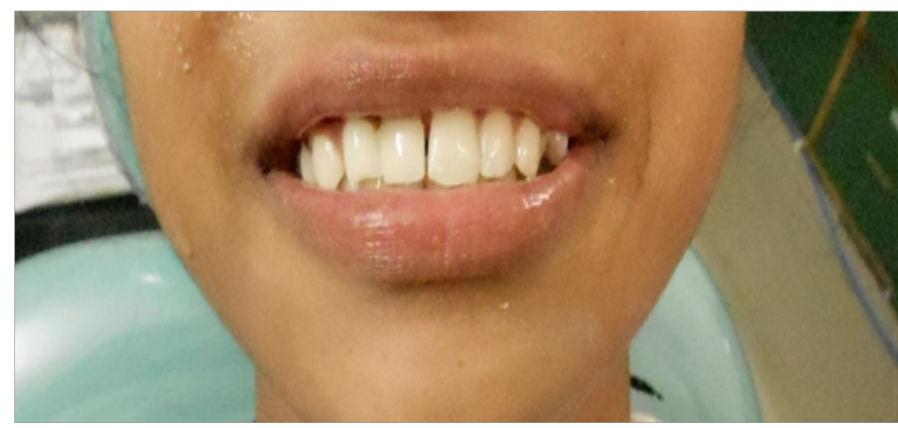

Figure 9: Esthetics after crown cementation.

The case was under observation two years without any untoward event.

\section{Discussion}

The anterior region of the maxilla is frequently termed as the aesthetic zone due to its high visibility and influence on facial appearance. Single tooth implant replacement in this region can present many clinical challenges. Not only must the crown conform in contour, shade, and texture to its neighbors, but the gingiva must also be in symmetry and harmony with the adjacent tissues ${ }^{[7,8]}$.

Immediate implant placement is indicated in cases of tooth extraction due to trauma, root fracture, root perforation, root resorption, unfavorable crown: root ratio and with no dehiscence or fenestration defect ${ }^{[9]}$. Contraindications include site with active infection, insufficient bone apical to tooth socket apex $(<3 \mathrm{~mm})$ and wide or long gingival recession ${ }^{[10]}$. In the present case under discussion the patient was having the history of trauma because of which the root was left inside whose coronal aspect was sub gingival in nature. There was no other possible restorative means available for this broken tooth for which immediate implant was decided to be the most appropriate means of future restoration.

Dental implants are becoming the most popular method of replacing lost natural dentition ${ }^{[11]}$. Esthetic replacement of the natural tooth system with implants will grow increasingly more common as patients seek esthetic enhancement and/or tooth replacement of their natural dentitions ${ }^{[12,13]}$. The focus of implantology over the past years has shifted from basic tooth replacement for function to include attention being paid to the aesthetic requirements of both the teeth and soft tissues surrounding them. Various protocols are being developed to ensure predictable, long lasting and esthetic implant supported restorations ${ }^{[1,15]}$. Implant designs and surface treatments are changing to achieve earlier and greater bone to implant contact. Manufacturers are responding with improved abutment prosthetic designs which more closely approximate the natural crown contours, and ceramic abutments are being introduced which help prevent 'metal show through' in cases involving thin friable gingival tissues.

As we have learned, once a maxillary anterior tooth is extracted, collapse of the socket wall begins in a buccal to palatal direction. This is accentuated even more in a socket with a thin or non-existent buccal plate. In addition, the crestal height of the extraction socket begins to move apically. This can leave a large concavity in the buccal gingival tissue, resulting in a prosthesis that will not be symmetrical to the adjacent dentition. Grafting the socket at the time of extraction and/or immediate implant placement are methods to help minimize soft and hard tissue changes, and ensure optimum esthetics and maximum longevity of the implant ${ }^{[16-21]}$. Meticulous planning is necessary for implant placement in the esthetic zone.

Proper examination, diagnosis and treatment planning, are necessary for esthetic and functional success of anterior single-tooth implants. To achieve prosthetically desired parallelism between implants or teeth, the clinician can place an angled abutment. Angulations of as much as 15 degree are easy to correct with pre angled components. Greater angulation correction may be possible with either pre angled parts or custom made components. The clinician has the choice of either prefabricated or customized abutments. While standard sizes and dimensions are sufficient for posterior restorations, their application in the anterior maxilla may not lead to an optimal esthetic final result. If support of the surrounding tissues is the primary objective, custom made abutments may be necessary for each individual situation. in our case the apical portion of implant had to be place palatally as a result of which the direction of the coronal part of the implant was labial to adjacent tooth. To minimize the angulation of the crown and to maintain the a parallesim an 
angulated abutment of 15 degree was placed so that the resultant crown could be placed and the labial aspect of crown was maintained in the same line of the adjacent incisors and canine. But the adverse effect was the shifting of apical portion of crown apically as compared to upper left central incisor. We could find no means to restore the esthetics but to replace the apical portion of the crown with colour very much similar to the gingiva. This gingival prosthesis could mimics the natural dention restoring the anterior esthetcs of the patient.

Case selection is very important, as; if the immediate placement and temporization procedures are pushed too far, fibrous attachment formation as opposed to osseointegration can result. This can create the possibility of failure and the need to remove/replace the implant and possibly graft the hard and soft tissues at the implant site, increasing the cost to the patient and/ or doctor, increasing the number of appointments and treatment time, and decreasing the satisfaction of the patient and doctor. The clinician must be aware of the advantages and limitations of a proposed treatment and negotiate the best health-esthetic compromise for the situation, and long-term health parameters must always be evaluated. Patients will accept our recommendations regarding longer treatment and healing times if they understand that their best interests are being considered. However the long term oral hygiene maintaince is the key to success about which our patent have been explance and being regularly evaluated.

\section{Conclusion}

The immediate implant placement approach has been studied extensively since being introduced. Evidence available indicates that it is a successful procedure that may benefit patients. However, careful planning and case selection are needed to ensure implant success and final esthetic outcomes.

\section{Conflict of Interest: Nil.}

\section{References}

1. Brånemark, P.I., Adell, R., Breine, U., et al. Intra-osseous anchorage of dental prostheses, I: Experimental studies. (1969) Scand J Plast Reconstr Surg 3(2): 81-100.

2. Flanagan, D. Immediate placement of multiple mini dental implants into fresh extraction sites: A case report. (2008) J Oral Implantol 34(2): $107-110$

3. De Rouck, T., Collys, K., Cosyn, J. Immediate single tooth implants in the anterior maxilla: A 1-year case cohort study on hard and soft tissue response. (2008) J Clin Periodontol 35(7): 649-657.

4. Ataullah, K., Chee, L.F., Peng, L.L., et al. Implant placement in extraction sockets: A short review of the literature and presentation of a series of three cases. (2008) J Oral Implantol 34(2): 97-106.

5. Schropp, L., Kostopoulos, L., Wenzel, A. Bone healing following immediate versus delayed placement of titanium implants into extraction sockets: A prospective clinical study. (2003) Int J Oral Maxillofac Implants 18(2): 189-199.

6. Quirynen, M., Van, Assche, N., Botticelli, D., et al. How does the timing of implant placement to extraction affect outcome? (2007) Int J Oral Maxillofac Implants 22(Suppl): 203-223.

7. Dhanzajani, P.J., Al-Rafee, M.A. Single Tooth Implant Implant Restorations : A Retrospective Study. (2005) Implant Dent 14(2): 125-130. 8. Tepret, F., Seitgoz, A., Basa, S. Immediately Loaded Anterior Single-Tooth Implants: Two Cases. (2005) Implant Dent 14(3): 242-247.

9. Jordi, Ortega-Martínez., Tania, Pérez-Pascual., Santiago, Mareque-Bueno., et al. Immediate implants following tooth extraction. A systematic review. (2012) Med Oral Patol Oral Cir Bucal 17(2): e251261.

10. Douglas, G.L., Merin, R.L. The immediate dental implant. (2002) J California Dental Association 30(5): 362-365.

11. Creughers, N.H., Kreulen, C.M., Snoek, P.A., et al. A Systemic Review of Single Tooth Restorations Supported by Implants. (2000) J of Dent 28(4): 209-217.

12. Petrungaro, P.S. Blending Conventional Grafting Techniques with Current Trends in Anterior Implant Reconstruction Part II : The Use of Regenerative Membranes to Correct Ridge Defects. (2000) The Journal of Cosmetic Dentistry 16(3): 30-37.

13. Garber, D.A., Belser, U.C. Restorative Driven Implant Placement with Restoration Generated Site Development. (1995) Compend Contin Educ Dent 16(8): 796-804.

14. Petrungaro, P.S. Replacing the Natural Tooth System in the Aesthetic Zone: Immediate Loading and Provisionalization of Single Tooth Implants to Deliver the Foundations for Function and Esthetics. (2001) The Journal of Cosmetic Dentistry 16(4): 38-44.

15. Sclar, A.G. Ridge preservation for optimum esthetics and function: The Biocol technique Postgraduate Dentistry. (1999) 6: 3-11.

16. Elian, N., Cho, S.C., Froum, S., et al. A Simplified socket classification and repair technique. (2007) Pract Proce aesthet dent 19(2): 99-104.

17. Bunyaratavej, P., Wang, H.L. Collagen membranes: a review. (2001) J Periodontol 72(2): 215-229.

18. Wang, H.L., Tsao, Y.P. Mineralized bone allograft-plug socket augmentation: rationale and technique. (2007) Implant Dent 16(1): 33-41.

19. Jackson, B.J., Morcos, I. Socket grafting: a predictable technique for site preservation. (2007) J Oral Implantol 33(6): 353-364.

20. Sclar, A.G. Strategies for management of single- tooth extraction sites in aesthetic implant therapy. (2004) J Oral Maxillofac Surg 62(9 Suppl 2): 90-105.

21. Petrungaro, P.S. Bone Grafting at the Time of Extraction : A New Technique for Achieving Natural Bone and Tissue Contours in Esthetic Tooth Replacement. (2000) The Journal of Cosmetic Dentistry 16(1): $30-45$.
Ommega Online Publisher

Journal of Dentistry and Oral Care

Short Title : J Dent Oral Care
ISSN: 2379-1705

E-mail : dentistry@ommegaonline.com website: www.ommegaonline.org 